\title{
Contre Saint-Proust ou la fin de la littérature
}

Dominique Maingueneau

Paris: Belin, 2007

\section{Maingueneau e os imaginários românticos da criação literária}

Em Contre Saint-Proust ou la fin de la littérature, Dominique Maingueneau investe, em um posicionamento polêmico, contra os moinhos de vento dos territórios da Literatura, que sonham e se imaginam divinos gigantes: "A Literatura morreu, mas a imensa multidão de seus fiés parece ignorar sua morte" (: 7). Escolhe um oponente de peso, a concepção do eu criador literário celebrada por Proust, em Contre Sainte-Beuve. A perspectiva discursiva facultaria uma consciência mais crítica do término de um regime de produção literária chamado de Literatura e cujo representante mais emblemático seria o romancista Marcel Proust.

Em um regime estético inaugurado pelo romantismo alemão, o eu verdadeiro do poeta encontra um eco na filosofia da criação bergsoniana. Corresponde à recusa da vida exterior, superficial e mundana, que tem como seu corolário uma atividade de "escritor", conversas de salão e artigos de jornais, ou seja, um conjunto de práticas que o crítico Sainte-Beuve representa. Essa é a concepção de literatura que se torna dominante nos anos 1960, quando as abordagens reunidas sob o nome de Nova Crítica descartam em uníssono o entorno institucional e biográfico, e atacam uma história literária limitada a um "estudo atomista do "contexto da criação" (: 27).

A abordagem crítica cujo foco é a consciência criadora só seria pertinente para a leitura de obras de autores dos séculos XIX e XX que compartilham esses pressupostos, e não dá conta da diversidade literária em matéria de gêneros, nem de suas dimensões históricas e geográficas. O discurso enquanto objeto de investigação traz a Análise do Discurso para o cerne da "própria construção dos protocolos de pesquisa e das interpretações" (: 42). Desmonta-se a falsa oposição entre Proust e Sainte-Beuve, eu profundoeu criador e eu superficial-eu social, o foro íntimo de criação da obra e as circunstâncias de sua criação.

É apresentado um programa de abordagem discursiva do literário, as circunstâncias exteriores à obra são redimensionadas como espaços sociais e institucionais de trocas, negociações entre palavra pública, palavra privada, e dispositivos interacionais. A substituição de "texto" ou "estrutura" por "discurso" implica uma outra concepção da linguagem e da literatura, esta não mais refletindo o mundo social ou expressando o mundo interior de um $e u$ criador, mas deles participando. 
A morte do autor tem como corolário a perda da oralidade, concepção teórica que se radicalizaria na escritura barthesiana. Para além do encontro entre os dois ausentes que são o leitor, destinatário não presente no momento da escrita, e o autor fantasmado, a obra também participa de um espaço institucional e das representações dos modos literários de criá-la, consumi-la e conservá-la. É levado em conta, igualmente, seu campo de forças, conceito fundamental dos trabalhos de Bourdieu, em que se confrontam posicionamentos estéticos de grupos em posição de rivalidade ou aliança, visando alcançar posições de dominância e apropriar-se, fundar e gerir uma memória ou arquivo. Instituição, campo e arquivo encontram-se imbricados de diferentes modos: nos regimes anteriores ao romantismo predominariam aspectos institucionais, o romantismo se estruturaria em torno dos conflitos do campo e, na atualidade, estaríamos vivendo em um regime no qual a criação literária se vê fortemente sobredeterminada pelas obras do passado.

Maingueneau retoma a categoria dos discursos constituintes ${ }^{1}$, que compreende os discursos religioso, estético e filosófico, "falas últimas de uma coletividade", os quais "se autorizam pelo Absoluto para dar sentido aos atos da coletividade" (: 60), jogando nos limites entre a linguagem e o indizível. São discursos que devem operar seus modos de emergência e legitimação, compartilham o oferecimento de um sentido inesgotável, uma vez que sua Fonte é o absoluto, e exigem um quadro hermenêutico e intérpretes competentes.

Campo, espaços institucionais e lugares de sociabilidade, quando referidos ao discurso literário, são apresentados, então, como fronteiras, um entrelugar marcado pela paratopia ${ }^{2}$, que Maingueneau define como "uma difícil negociação, no próprio discurso, entre o lugar e o não lugar” (: 67). A paratopia pode assumir diversos aspectos, mas é sobretudo enunciativa, ou seja, um processo em que a obra exibe suas condições de possibilidade.

Contre-Saint Proust traz uma visão renovada das relações entre vida e obra literária, não mais a obra que se explica pela vida do autor, como na crítica biográfica cujo patrono é Sainte-Beuve, mas tampouco a vida cortada da obra, como afirma a estética proustiana: "A elaboração das condições da criação é constitutiva dessa criação" (:76). E as lutas no campo literário

${ }^{1}$ Cf. Maingueneau, Dominique \& Cossutta, Frédéric. "L’analyse des discours constituents". Langages, n. 117, 1995: 112-25. Cf. igualmente "L'Analyse des discours constituants". Em: Mari, Hugo e outros (org). Fundamentos e dimensões da análise do discurso. Belo Horizonte: Carol Borges / Núcleo de Análise do Discurso/Fale-UFMG, 1999.

${ }^{2}$ Cf. Maingueneau, Dominique. Le contexte de l'oeuvre littéraire. Paris: Dunod, 1993. [O contexto da obra literária. Tradução Maria Appenzeller. São Paulo: Martins Fontes, 1995; 2ed. 2001]; Maingueneau, Dominique. Le discours littéraire: paratopie et scène d'énonciation. Paris: Armand Colin, 2004 [Discurso literário. Tradução Adair Sobral. São Paulo: Contexto, 2006]. 
resultam tanto de conflitos entre diferentes posicionamentos estéticos quanto de representações antagônicas, no sentido dramático da expressão, sobre quem tem legitimidade para a produção de uma obra, qual o percurso biográfico que a legitima e o pertencimento à instituição. São imaginários representados na cena enunciativa da obra, mais especificamente em sua cenografia enunciativa, na qual Maingueneau localiza três instâncias: a pessoa, o escritor e o inscritor. Tais instâncias não devem ser articuladas como se fossem sucessivas ou desfolhadas como diferentes níveis de enunciação, mas antes consideradas como uma estrutura análoga à do nó borromeu, que necessita, para produzir efeitos, da amarração dos três anéis.

Cada uma das três instâncias produz determinados enunciados, o que levaria à tentação de categorizá-los em uma tipologia, diferenciando, por exemplo, os enunciados do cotidiano (pessoa), entrevistas dadas a jornalistas (escritor) e a "obra" propriamente dita (inscritor). Algumas fronteiras permanecem difíceis de traçar: "De fato, a fronteira entre o interior e o exterior da obra 'canônica' não se encontra previamente definida, mas é renegociada em cada caso: Beaumarchais não é Flaubert, Voltaire não é Mallarmé” (: 86). Há textos de figuração, que encenam o processo criativo, e textos de regulação, em que o criador negocia sua inserção no campo e seu estatuto institucional. A distribuição dos gêneros textuais dos dois lados da fronteira apresenta maior ou menor uniformidade, conforme aspectos conjunturais, relacionados com as formações discursivas. A tendência romântica para a obra absoluta faz proliferar textos autobiográficos e ensaios de estética que vêm explicitar os posicionamentos do "criador", diante de novos estatutos e imaginários de autorialidade e sua conseqüente necessidade de legitimação. A dimensão de autorialidade deverá levar em conta, igualmente, os resultados de decisões editoriais, que produzem obras, ao recortar e redistribuir determinados textos, contribuindo para novas configurações de gênero e novas leituras, como no caso de Contre Sainte-Beuve, publicado mais de trinta anos depois da morte de Proust, e resultante das decisões tomadas por Bernard de Fallois.

Paratopia e autorialidade marcam respectivamente a desterritorialização da enunciação literária e a tentativa de recentralizar a dispersão dos espaços na figura do autor: literatura e escritor situam-se em um não-lugar enunciativo e a instância criadora é instável. Encontramos aqui a mobilidade e plasticidade do sujeito da enunciação, os jogos de linguagem que nos fazem procurar onde ele não se encontra, podendo a déchirure de que nos fala Maingueneau ser aproximada do corte do Sujeito barrado em Lacan.

Ao contestar os imaginários românticos da criação literária, Dominique Maingueneau questiona ainda "a face oculta dos estudos literários, os modos de organização e legitimação dos especialistas e de seus enunciados" (: 105), que operam como se a literatura fosse um objeto estável. Ora, os 
estudos literários constituem um campo, em que grupos rivais obedecem aos mesmos confrontos e posicionamentos em conflito que foram apontados no campo literário.

Para demonstrar sua hipótese, o lingüista rememora a distribuição de tarefas e objetos que ocorreu historicamente, nas universidades francesas, entre lingüistas e filólogos, de um lado, entre filólogos e especialistas em estilística, de outro, um movimento que culmina, no final do século XIX, com a instauração da disciplina de História literária. Também ocorre uma distribuição de objetos e tarefas entre os universitários, dedicados à erudição, e os ensaístas, autores de interpretações e discussões estéticas destinadas a um público mais amplo.

Nos anos 1960, na França, o aumento brutal dos contingentes de alunos das faculdades de Letras exigiu igual aumento no número de professores, privilegiou a seção de Letras Modernas, que prescindiu de uma formação humanista, e demandou uma produção de obras críticas despidas de saber filológico ou erudito. A Nova Crítica ocuparia, então, um espaço institucional e editorial, e disputa com a Literatura o dizer do sentido da existência, oferecendo métodos interpretativos fundamentados nas ciências humanas e grande liberdade de interpretação. Por alguns breves anos, os ensaístasescritores, cujo representante emblemático é Roland Barthes, acumulam a aura literária herdada do século XIX e o prestígio científico das novas abordagens do texto literário.

Instaura-se um espaço de pesquisa, o que obriga os especialistas de literatura a práticas institucionais formatadas originalmente pelas ciências hard e à competição por financiamento. Cria-se uma distância entre o professorcrítico e o professor-pesquisador. O crítico é um leitor atento que interpreta os textos com sua cultura e intuição, em um movimento de mimetismo e competição entre o comentário e a obra. O pesquisador trabalha atento a protocolos de exploração de dados; como nas ciências humanas, o objeto será construído a partir de problemas formulados com precisão.

$\mathrm{O}$ estudo da literatura, contudo, implica uma tensão entre o modelo de pesquisa das ciências humanas e sua "especificidade irredutível" (: 121), levando à interrogação de sua existência enquanto disciplina. A mesma incerteza surge quando se trata de definir o objeto "literatura". Formulase uma dupla interrogação: a "literatura" será vista como um patrimônio composto pelas obras do cânone ou pela ótica do complexo fazer literário? O especialista de literatura é um pesquisador de ciências humanas ou um "hermeneuta solitário diante de uma Fonte de sentido"? (: 129)

Somos cientistas ou profetas? A “dupla linguagem” sustentada nos anos 1960 pela crítica temática seria, atualmente, preservada por duas abordagens complementares, a da erudição e aquela que tem como referente a filosofia e a psicanálise, que radicalizam a dimensão hermenêutica. A erudição traz 
a vantagem de "produzir conhecimentos fora de uma verdadeira conceitualização e modelização" (: 132), mas penso que isso não a exime de posições teóricas implícitas na escolha dos "novos conhecimentos" que ela colocará à disposição dos intérpretes. Roland Barthes semiólogo ilustraria a incerta fronteira entre hermenêutica e ciência, e a Análise do Discurso permitiria conciliar, institucionalmente, as duas posições, ao apontar espaços comuns de reflexão, em torno das problemáticas da linguagem.

Voltamos, então, à questão da morte da Literatura e da emergência de um novo regime de "inscrições", entre as quais se encontra a literatura. No século XIX, a Literatura constitui o espaço de fala de maior prestígio; hoje, tendo-se tornado intransitiva, perderia um lugar de supremacia, substituída pelas "múltiplas regiões do universo multimediático" (: 149). Os problemas da sociedade e as teses políticas são, agora, debatidos e os modelos de comportamento, propostos em outros espaços de fala, como a propaganda, a música popular e o cinema. Durante dois séculos, a criação literária esteve voltada para novos modos de apreender a realidade. Seu impacto estava ligado ao uso de novas tecnologias pela imprensa, em um estágio industrial, e moldava a opinião pública, com um efeito transformador das estruturas sociais e intelectuais. $\mathrm{O}$ esgotamento de seu poder de redefinir formas de escrita poderia ser verificado em certa perda de aplicabilidade da noção de campo, uma vez que se enfraquecem os antagonismos entre diferentes posições.

A atual ausência de polêmicas literárias seria o índice de um esvaziamento de disputas simbólicas, com a passagem da lógica do campo para a lógica do arquivo: a Literatura se vê reduzida à função de um patrimônio, memória e reserva de temas e motivos que alimentam a produção multimídia. As lutas entre diferentes posicionamentos foram substituídas pela "imensa biblioteca, sem disputas" (: 155). O mesmo fenômeno pode ser observado na venda de livros na França, em que as obras de Molière, Balzac ou Camus vendem mais do que as de autores contemporâneos. Mas vale indagar o quanto esses autores venderam em seu tempo e até que ponto sua presença nas antologias escolares e em programas de exames repercute nas tiragens atuais. Ou o leitor não procura ler aquilo que aprendeu a ler ou que tem que ter lido?

Um outro índice de perda de força simbólica seria o fato de a Literatura tomar como tema seu próprio Thesaurus: a relação entre a literatura e as obras já escritas vem substituir a relação entre a literatura e o mundo. Essa força intertextual, todavia, não pode ser vista como um processo análogo ao que resulta das teorias da imitação do neoclassicismo?

Penso que a concorrência multimidiática à supremacia da literatura tampouco representa uma nova tensão entre campos discursivos de atividades rivais, uma vez que atualiza, em termos de texto/imagem digital, as transformações que as novas tecnologias do impresso impuseram à 
criação literária na França do século XIX. O romance de folhetim, a edição popular e o uso de ilustrações criaram a possibilidade de ministrar a um novo contingente de leitores o phârmakon procurado na leitura. O triunfo daquele tipo de impresso não deixou de ser registrado, aliás, pelo próprio crítico Sainte-Beuve, em Da literatura industrial (1839), como um desastre que comprometia a "coisa literária". Como enfatiza Maingueneau, o "império do livro", na "idade do Estilo", foi tributário da imprensa escrita. A interdependência entre o livro e a web, assim como as novas modalidades digitais reproduzem de certo modo, a meu ver, a relação anterior entre livro impresso e imprensa escrita. Da mesma maneira, os novos modos digitais de escrever também facultam, como na era "Gutenberg" industrial, a produção de uma subliteratura. Na França, a situação de monopólio do regime da Literatura apontada pelo lingüista pode ser explicada por um domínio dos imaginários e da imaginação herdado das lutas políticas anteriores e canalizado pela escola da III ${ }^{\mathrm{a}}$ República. As causas políticas de seu atual declínio ainda merecem ser exploradas.

Celina Maria Moreira de Mello

[UFRJ] 